\title{
Where is UK general dental practice going?
}

\section{H. Harrison*}

\author{
Dentistry is a fundamental part of healthcare; without it a large \\ proportion of the population would suffer severe detriment to \\ their general health. However, in order to achieve our \\ professional aims we have to pursue the business of dentistry.
}

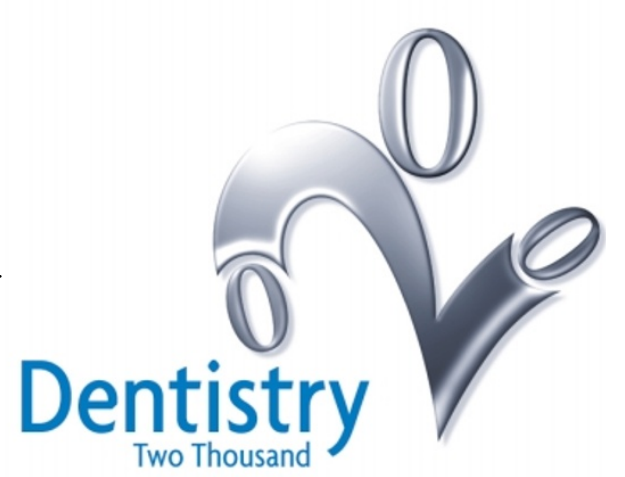

This is a business like any other. If a proper service is to be provided, we have to present it in an easily understood and recognisable manner to our market (the general public). In other words we have to brand and market our product.

Dentistry in the UK has held a unique position among the professions over the last 50 years or so. We have been independent sub-contractors within the National Health Service. Under this arrangement there has been clearly demarcated funding for dentistry (whether we consider this to have been a sufficient sum or not is incidental to this debate), an image presented to the public of a reliable, trustworthy, accessible and affordable service which the average man or woman can understand. At the same time, dentists have been able to control their working environment according to their own personal aspirations, skills and preferences and earn a comfortable living. Although the stresses and strains of running a dental practice may not suit us all, a high proportion of UK dentists see their identity as dentists wrapped up closely with the style and type of practice in which they work. The potential for building an asset and financial independence forms much of the career structure and satisfaction of the job.

The debate of the nineties does seem to have been 'NHS or private?. Many opinions have been expressed and much comment reflecting on greener pastures over the fence but, having worked in and run practices in both the NHS and private sector, I am now of the opinion that the real issues have yet to be faced by most of us. The very existence of NHS dentistry has shielded both NHS and private practices from the market forces that prevail for most other service providers in the business world.

As far as the general public are concerned, NHS has represented appropriate,

affordable, reliable and safe dentistry. This has been a very effective passive marketing tool for all dental practices for whom, over most of the last 50 years, the main challenge has been the efficient provision of dentistry within the recognised framework. In this context, most dentists have managed to run a successful dental practice. Private practices have emerged to serve a series of niches of dissatisfaction with the NHS provision. But the landscape is definitely changing. Government funding for NHS dentistry, as

Dentistry 2000, the biggest single dental event ever to be held in Great Britain, takes place between 6 and 8 April in Birmingham next year.

To hear more about this subject, why not come along to the session Branding - Image Counts on Friday 7th April from 10am-12 noon.

For further details, contact the BDA conference office on 02079350875 extension 233 or 286.

we all know, is declining, but new sources of funding are emerging. Simple comparisons with the USA indicate that the UK dental market has significant potential for growth. Can the bodies corporate precipitate growth of the market by means of their marketing and sales strategy or will they simply muscle in and cream off the best opportunities for providing dentistry? What about the insurance industry? Will insurance companies provoke growth in the market and how much control will they seize? The government does not appear to want to withdraw from the scene either. Will the politicians attempt to retain control via clinical governance?

No one is yet able to provide the answers to these questions although there are many informed opinions on the subject. As I see it, there is one certainty; all of the present activity will raise the profile of dentistry in the minds of the public. Patients will have ever increasing awareness of the market and a greater and greater desire to choose. While dentistry will remain an essential service for general public health the demand for 'desire led' service is likely to expand and develop. The result of all of this will be to widen the playing field and open it up, making it essential to employ much more sophisticated marketing and business skills than we have ever needed to in the past.

So I, like all of my colleagues, need to understand where that leaves my own practice in, say, the next five or ten years. The BDA understands the need to position itself to be able to offer practical support to dentists in this area. Recognition of the quality and skills in general dental practices, presented in a form which serves as a useful marketing tool, is an area in which the BDA is currently working. Since we can have no accurate prediction of the future the best option is to draw together as much expert opinion as possible in order that we can respond to the changes as they happen. The BDA has drawn such a group together for a Friday session at Dentistry 2000 entitled Branding - Image Counts.

Dentistry is a science, a skill and often a beautiful art, and we are the individuals trained and able to do it. No matter how much politicians, civil servants, managers or insurers attempt to control the provision of dentistry, dentists have to be part of the equation. Without the dentists, the service of dentistry cannot be provided. This is the responsibility, which we must grasp, and grasp quickly if we are to retain the professional identity which we currently enjoy.

* Helen Harrison is a general dental practitioner in
Cambridge. 